\title{
Mechanical and structural response of radiation-damaged pyrochlore to thermal annealing
}

\author{
Claudia E. Reissner ${ }^{\mathrm{a}, *}$, Vladimir Roddatis ${ }^{\mathrm{b}}$, Ulrich Bismayer ${ }^{\mathrm{c}}$, Anja Schreiber ${ }^{\mathrm{b}}$, \\ Herbert Pöllmann ${ }^{\text {a }}$, Tobias Beirau ${ }^{\text {a,* }}$ \\ a Institute of Geosciences and Geography, Mineralogy/Geochemistry, Martin-Luther-University Halle-Wittenberg, Von-Seckendorff-Platz 3, 06120 Halle (Saale), Germany \\ ${ }^{\mathrm{b}}$ Deutsches GeoForschungszentrum GFZ, Helmholtz-Zentrum Potsdam, Telegrafenberg, 14473 Potsdam, Germany \\ ${ }^{\mathrm{c}}$ Department of Earth Sciences, University of Hamburg, Grindelallee 48, 20146 Hamburg, Germany
}

\section{A R T I C L E I N F O}

\section{Keywords:}

Pyrochlore

Irradiation effect

Nanoindentation

Annealing

In situ transmission electron microscopy (TEM)

\begin{abstract}
A B S T R A C T
Nanoindentation has been employed to probe the mechanical properties [indentation hardness $(H)$ and elastic modulus $(E)]$ of radiation-damaged pyrochlore before and after step-wise thermal annealing up to $900 \mathrm{~K}$. Three natural $\mathrm{U}$ and/or Th containing samples with increasing degree of disorder have been investigated (i.e., Panda Hill: $1.8 \mathrm{wt} \% \mathrm{ThO}_{2}$, maximum life-time alpha-decay event dose $\sim 1.6 \times 10^{18} \alpha$-decay g ${ }^{-1}$; Blue River: $11.9 \mathrm{wt} \%$ $\mathrm{UO}_{2}$, maximum life-time alpha-decay event dose $\sim 115.4 \times 10^{18} \alpha$-decay g ${ }^{-1}$; and Miass: $7.2 \mathrm{wt}^{2} \mathrm{ThO}_{2}$, maximum life-time alpha-decay event dose $\sim 23.1 \times 10^{18} \alpha$-decay $\mathrm{g}^{-1}$ ). Complementary investigations by photoluminescence and Raman spectroscopy and in-situ annealing transmission electron microscopy (TEM) allowed us to follow the structural evolution. Therefore, a comprehensive understanding of the thermally induced structural reorganization process was obtained. Recrystallization has found to start above $500 \mathrm{~K}$ in the pyrochlores. Due to the increasing structural order a general hardening of the mechanical properties was observed. Miass pyrochlore (highest degree of structural damage of the investigated samples) reaches a polycrystalline state after annealing. While lesser damaged, but also highly disordered Blue River pyrochlore (containing small preserved crystalline domains) has found to transform into a single crystal. The recrystallization of both pyrochlore samples was followed by in-situ TEM at 800 and $750 \mathrm{~K}$, respectively.
\end{abstract}

\section{Introduction}

Phases with pyrochlore structure $\left(\mathrm{A}_{2} \mathrm{~B}_{2} \mathrm{O}_{7}\right)$ display in all their chemical varieties (around 450 synthetic compounds are currently known) a multitude of technically important characteristics, such as, catalytic abilities, ferromagnetism, luminescence, giant magnetoresistance, and piezoelectricity [e.g., 1-5]. Several studies have focused on synthetic pyrochlore structures with varying chemical composition and synthesis conditions [e.g., 6,7]. Furthermore, they are also promising host phases for the long-term disposal of actinides in ceramics or glass-ceramics that can load, e.g., up to $\sim 35 \mathrm{wt} \%$ plutonium [2,8-16]. Strachan et al. [17] showed that the incorporation of weapons-grade ${ }^{238} \mathrm{Pu}$ into the pyrochlore structure will lead to its amorphization, however, no evidence of microcracking or dissolution was found. Likewise, the possible incorporation of $\mathrm{Np}^{6+}$ has been proposed [18].

The pyrochlore structure with ideal formula ${ }^{\mathrm{VII}} \mathrm{A}_{2}{ }^{\mathrm{VI}} \mathrm{B}_{2}{ }^{\mathrm{IV}} \mathrm{X}_{6}{ }^{\mathrm{IV}} \mathrm{Y}$ crystallizes in space group $F d \overline{3} m$ [19-22]. It is an anion-deficient derivative of the $\mathrm{AX}_{2}$ fluorite structure-type. The cubic pyrochlore structure consists of 8-fold-coordinated $\mathrm{A}$ cations arranged in $\mathrm{A}_{2} \mathrm{Y}$ chains and corner- sharing $\mathrm{BX}_{6}$ octahedra (Fig. 1) [22,24-26]. Natural pyrochlore can incorporate a large variety of different cations, such as $\mathrm{Na}, \mathrm{Ca}, \mathrm{U}, \mathrm{Th}, \mathrm{Y}$, and rare earth elements (REE), as well as $\mathrm{Fe}^{2+}, \mathrm{Mn}, \mathrm{Sn}^{2+}, \mathrm{Sb}, \mathrm{Bi}, \mathrm{Sr}$, $\mathrm{Ba}, \mathrm{Pb}, \mathrm{K}$ and $\mathrm{Cs}$ in smaller quantities on the A position. The $\mathrm{B}$ position is usually occupied by $\mathrm{Nb}, \mathrm{Ta}, \mathrm{Ti}, \mathrm{Fe}^{3+}, \mathrm{Zr}$, and $\mathrm{Sn}^{4+}$ [27]. The $\mathrm{X}$ and $\mathrm{Y}$ positions are occupied by oxygen, however on the $\mathrm{Y}$ position, $\mathrm{OH}$ groups and $\mathrm{F}$ can be incorporated as well [27]. Up to $30 \mathrm{wt} \% \mathrm{UO}_{2}$ and $9 \mathrm{wt} \% \mathrm{ThO}_{2}$ have been found in natural pyrochlore [28]. As they are often exposed to nuclear radiation for millions of years, due to incorporated $\mathrm{U}$ and $\mathrm{Th}$, minerals have found to be adequate natural analogs for the study of the long-term behavior of possible crystalline host phases for nuclear waste disposal [29]. The incorporation of radiogenic elements leads to a structural damage and amorphization process (metamictization), mainly caused by the $\alpha$-decay of the unstable nuclei, which has been described in detail in literature [24,25,30,31]. During such an event an $\alpha$-particle and a heavy recoil nucleus are generated. While the latter (dissipating its energy by elastic collisions) displaces several thousands of atoms in its path through the periodic structure, inducing recoil cascades, the He core (major energy loss by electronic excitations) only

\footnotetext{
* Corresponding authors.

E-mail addresses: claudia.reissner@geo.uni-halle.de (C.E. Reissner), tobias.beirau@geo.uni-halle.de (T. Beirau).
} 


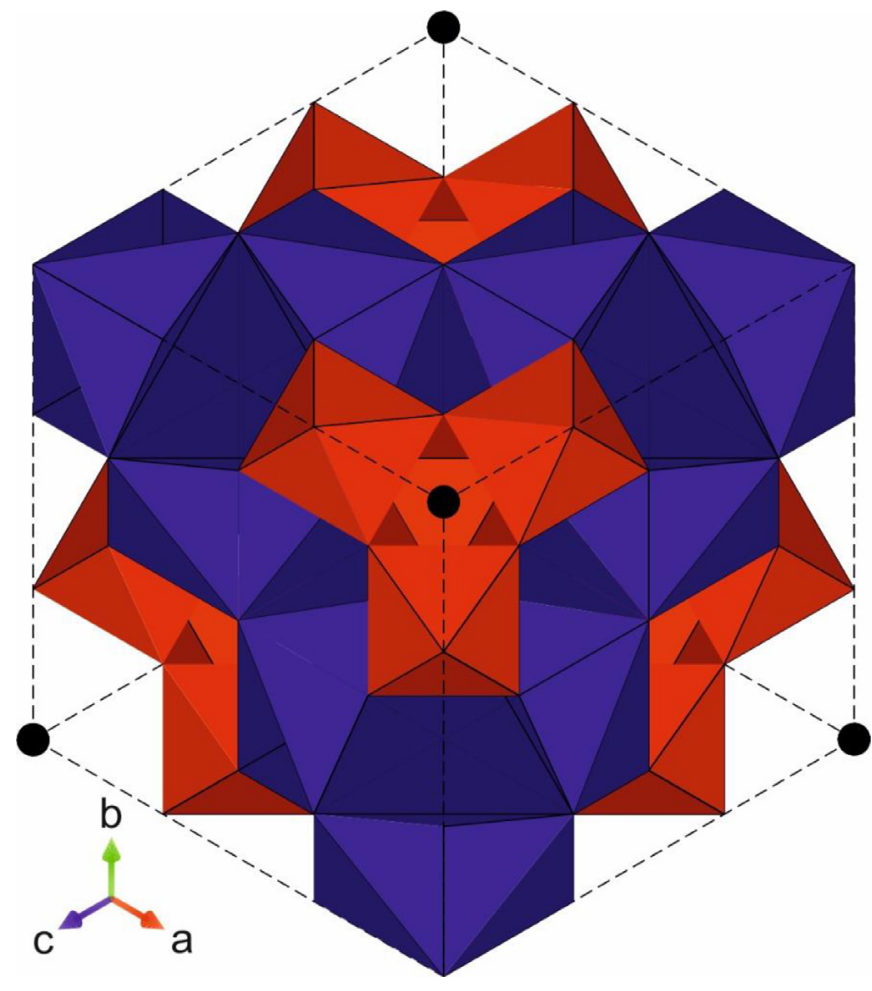

Fig. 1. Schematic representation of the ideal pyrochlore structure. The purple polyhedra comprise the A position, the red polyhedral the B position and the black atoms are located on the Y position. Dashed lines represent the unit cell. Data from [23]. This image was created using the VESTA software.

displaces several hundred atoms at the end of its trajectory. Due to the overlap and resulting percolation (at least for zircon [32]) of the disordered aperiodic regions, the long-range order becomes destroyed and finally an amorphous state will be established. The radiation damage and geochemical alteration in pyrochlore has been investigated in detail in literature [27,33-35]. The radiation-damaged state is metastable and thermal treatment can lead (at least partially) to structural reorganization. In pyrochlore, this recrystallization process has found to be accompanied by weight loss and an energy release that decreases with increasing crystallinity [36].

Various ion irradiation experiments have been conducted to investigate the general response of pyrochlore structure-types with different compositions to radiation damage [e.g., 37-41] and additional thermal annealing [e.g., 42-46]. It was found that the ordered pyrochlore structure first transforms into an anion-disordered pyrochlore structure and at higher fluences into a cation-disordered fluorite structure [47]. Recently, Xia et al. [48] reported the interesting case of ion irradiation related recrystallization processes at higher fluences in $\mathrm{Lu}_{2-\mathrm{x}} \mathrm{Ce}_{\mathrm{x}} \mathrm{Ti}_{2} \mathrm{O}_{7}$ pyrochlore phases. Janish et al. [49] investigated in-situ the recrystallization of an irradiated pyrochlore phase using transmission electron microscopy.

Up until now, very little has been known about the influence of radiation damage and subsequent thermal annealing on the mechanical properties of pyrochlore. Weber et al. [50] found the Vickers hardness to decrease due to structural damage in synthetic $\mathrm{Cm}$ doped pyrochlore ceramics. We undertook this study to shed light on the mechanical behavior of pyrochlore to help assess its suitability as a possible nuclear waste matrix. Nanoindentation enables the determination of the hardness and elastic modulus of three natural uranium and/or thorium containing pyrochlore samples, with different degrees of disorder, before and after step-wise annealing up to $900 \mathrm{~K}$ (not higher to avoid the increased formation of new phases [51]). Complementary investigations by photoluminescence and Raman spectroscopy and in-situ annealing transmission electron microscopy enable us to better understand the local structural evolution and its mesoscopic and macroscopic physical consequences.

\section{Samples and methods}

\subsection{Pyrochlore samples}

The selected and in the following described radiation-damaged pyrochlore samples (referred to as Panda Hill, Blue River and Miass) have been characterized in detail (origin, chemical composition, thermal behavior, suffered radiation dose and amorphous fraction) by Zietlow et al. [51].

The Panda Hill sample contains $1.8 \mathrm{wt} \% \mathrm{ThO}_{2}, 61.5 \mathrm{wt} \% \mathrm{Nb}_{2} \mathrm{O}_{5}$, $0.7 \mathrm{wt} \% \mathrm{Ta}_{2} \mathrm{O}_{5}$ and $0.2 \mathrm{wt} \% \mathrm{Nd}_{2} \mathrm{O}_{3}$, with a reported maximum lifetime alpha-decay event dose of $1.6 \pm 0.1 \times 10^{18} \alpha$-decay $\mathrm{g}^{-1}$ and an amorphous fraction of up to $\sim 28 \%$.

Blue River pyrochlore contains $11.9 \mathrm{wt} \% \mathrm{UO}_{2}, 46.5 \mathrm{wt} \% \mathrm{Nb}_{2} \mathrm{O}_{5}$ and $18.3 \mathrm{wt} \% \mathrm{Ta}_{2} \mathrm{O}_{5}\left(\mathrm{Nd}_{2} \mathrm{O}_{3}\right.$ content below the detection limit), with a reported maximum life-time alpha-decay event dose of $115.4 \pm 1.0 \times 10^{18}$ $\alpha$-decay $\mathrm{g}^{-1}$ and an amorphous fraction of $\sim 85 \%$. This sample is expected to be initially already partially recrystallized [51].

The Miass sample contains $7.2 \mathrm{wt} \% \mathrm{ThO}_{2}, 50.6 \mathrm{wt} \% \mathrm{Nb}_{2} \mathrm{O}_{5}, 2.0 \mathrm{wt} \%$ $\mathrm{Ta}_{2} \mathrm{O}_{5}$ and $1.0 \mathrm{wt} \% \mathrm{Nd}_{2} \mathrm{O}_{3}$, with a reported maximum life-time alphadecay event dose of $23.1 \pm 0.6 \times 10^{18} \alpha$-decay $g^{-1}$ and an amorphous fraction of $\sim 100 \%$.

Fragments from exactly the same specimens studied by Zietlow et al. [51] have been investigated in this work. Initially all samples had an octahedral shape, while the most radiation-damaged ones (Blue River and Miass) show a glassy luster. They were cut and polished plane-parallel to the crystallographic (111) plane (surface). Xu et al. [11] investigated a uranium containing pyrochlore zirconolite mixed ceramic (as it would occur in Synroc). They found the (001) plane of zirconolite to be parallel to the (111) plane of pyrochlore.

The investigated pyrochlore samples were step-wise annealed at 500, $600,700,800$ and $900 \mathrm{~K}$ each time for $16 \mathrm{~h}$ in air. After each annealing step they were cooled down to room temperature and indentation and spectroscopic measurements were performed on the same samples.

\subsection{Nanoindentation}

The mechanical properties were measured using a Nanomechanics iNano nanonindenter equipped with a diamond indenter tip (Berkovich geometry). A constant nominal strain rate of $0.2 \mathrm{~s}^{-1}$ was used. The sample stiffness $(S)$ was measured continuously during the loading process using the continuous stiffness mode (CSM) [see 52,53]. The instrument software calculated the hardness $(H)$ and the elastic modulus $(E)$ during the loading process according to Oliver and Pharr [54] with

$H=\frac{P}{A}$

where $P$ is the imposed load and $A$ the contact area between indenter and sample. The contact area is determined via the shape of the indenter $[53,55]$. The measured contact stiffness $(S)$ is related to the elastic properties of both the sample and indenter and the contact area through [56]

$S=\beta \frac{2}{\sqrt{\pi}} E_{r} \sqrt{A}$

where $\beta$ is a constant that depends on the indenter tip geometry (Berkovich geometry $\beta=1.05$ ) [53] and $E_{r}$ is the reduced modulus. 
Table 1

Hardness $(H)$ of pyrochlore samples Panda Hill, Blue River, and Miass after annealing at different temperature steps. All measurements were obtained at room temperature. The given values are averages of multiple measurements at indentation depths of 250-300 $\mathrm{nm}$.

\begin{tabular}{lllllll}
\hline Sample & Pristine & $500 \mathrm{~K}$ & $600 \mathrm{~K}$ & $700 \mathrm{~K}$ & $800 \mathrm{~K}$ & $900 \mathrm{~K}$ \\
\hline Panda Hill & $11.20 \pm 0.22$ & $10.91 \pm 0.39$ & $11.42 \pm 0.26$ & $12.20 \pm 0.21$ & $12.11 \pm 0.22$ & $11.51 \pm 0.20$ \\
Blue River & $7.35 \pm 0.13$ & $7.73 \pm 0.2$ & $8.21 \pm 0.12$ & $10.08 \pm 0.33$ & $10.75 \pm 0.40$ & $11.61 \pm 0.25$ \\
Miass & $7.51 \pm 0.28$ & $7.84 \pm 0.26$ & $7.93 \pm 0.25$ & $8.33 \pm 0.20$ & $11.94 \pm 0.63$ & $13.25 \pm 0.64$ \\
\hline
\end{tabular}

The reduced modulus takes into account that elastic displacement takes place in the indenter as well as in the sample [53] with

$\frac{1}{E_{r}}=\frac{\left(1-v_{i}^{2}\right)}{E_{i}}+\frac{\left(1-v^{2}\right)}{E}$

where $E$ and $v(0.27)$ are the elastic properties of the sample. While, $E_{i}$ and $v_{i}$ are the elastic modulus and Poisson's ratio of the indenter, respectively (for the diamond indenter $E_{i}=1141 \mathrm{GPa}$ and $v_{i}=0.07$ ). $H$ and $E$ values were averaged over an indentation depth of 250 to $300 \mathrm{~nm}$ with several indents. Fused silica was the reference material used for calibration.

\subsection{Transmission electron microscopy}

Specimens for transmission electron microscopy (TEM) studies were prepared using a Thermo Fischer (former FEI) dual-beam instrument Helios G4 UC by lift-out technique. Several lamellas were cut from each of the three samples and thinned down to about $100 \mathrm{~nm}$ thickness using $30 \mathrm{kV} \mathrm{Ga}^{+}$ions followed by final polishing at 5 and $2 \mathrm{kV}$. Final cleaning was performed by $\mathrm{Ar}^{+}$ions with an energy less than $1 \mathrm{kV}$ using a Gatan Duo Mill 600 setup. Transmission electron microscopy was performed using a FEI Tecnai F20XT TEM operated at $200 \mathrm{kV}$. The microscope was equipped with an EDAX Energy dispersive X-Ray (EDX) spectrometer used to verify chemical composition and a Fishione 2000 detector for High Angle Annular Dark Field (HAADF) imaging. In-situ TEM experiments were carried out using a single-tilt heating holder model 628 (Gatan).

\subsection{Spectroscopy}

Raman and photoluminescence spectroscopic measurements were performed using a Horiba XPlora ${ }^{\mathrm{TM}}$ PLUS confocal spectrometer. Spectra were collected in back-scattering geometry using a $638 \mathrm{~nm}$ laser and a long-working distance objective with magnification $50 \times$. The diameter of the laser spot on the sample surface was approximately $2 \mu \mathrm{m}$ and it was verified that laser irradiation does not change the sample due to undesired overheating. Additionally, measurements with a $532 \mathrm{~nm}$ laser were performed to differentiate between Raman and luminescence signals. Measurements were repeated at several points on the sample.

\subsection{Mass spectrometry}

Mass spectrometric data was obtained using a QMS 403D Aeolos Netzsch instrument. The sample was ground to a fine powder in an agate mortar and heated in an $\mathrm{Al}_{2} \mathrm{O}_{3}$ pan with a heating rate of $10 \mathrm{~K} / \mathrm{min}$.

\section{Results}

\subsection{Nanoindentation}

The pristine Panda Hill sample shows a hardness $(H)$ and an elastic modulus $(E)$ of $\sim 11.2 \mathrm{GPa}$ and $\sim 169 \mathrm{GPa}$, respectively (Tables 1,2 , Figs. 2,3). Step-wise annealing causes a steady increase in hardness and elastic modulus from 600 to $700 \mathrm{~K}$ reaching values of $\sim 12.2 \mathrm{GPa}$ and $\sim 203 \mathrm{GPa}$, respectively. Further annealing at $800 \mathrm{~K}$ increases only the elastic modulus to $\sim 217 \mathrm{GPa}$. After annealing at $900 \mathrm{~K}$ a slight decrease

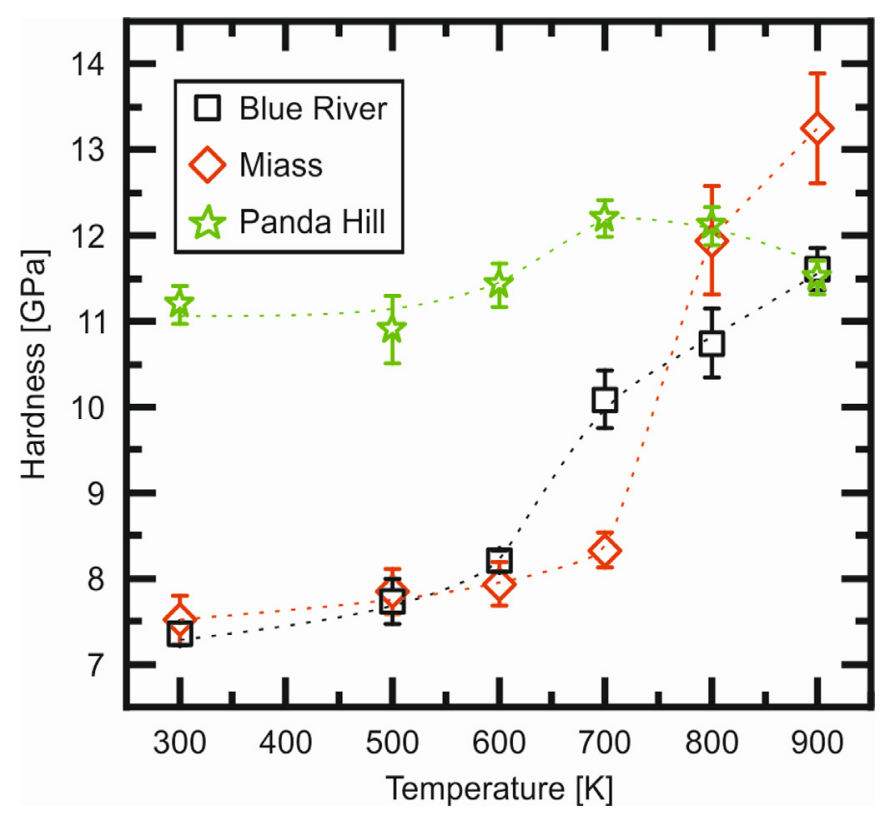

Fig. 2. Evolution of the average indentation hardness as a function of annealing temperature of pyrochlore samples Panda Hill (green stars), Blue River (black squares) and Miass (red diamonds). All measurements were obtained at room temperature. The lines are a guide for the eye.

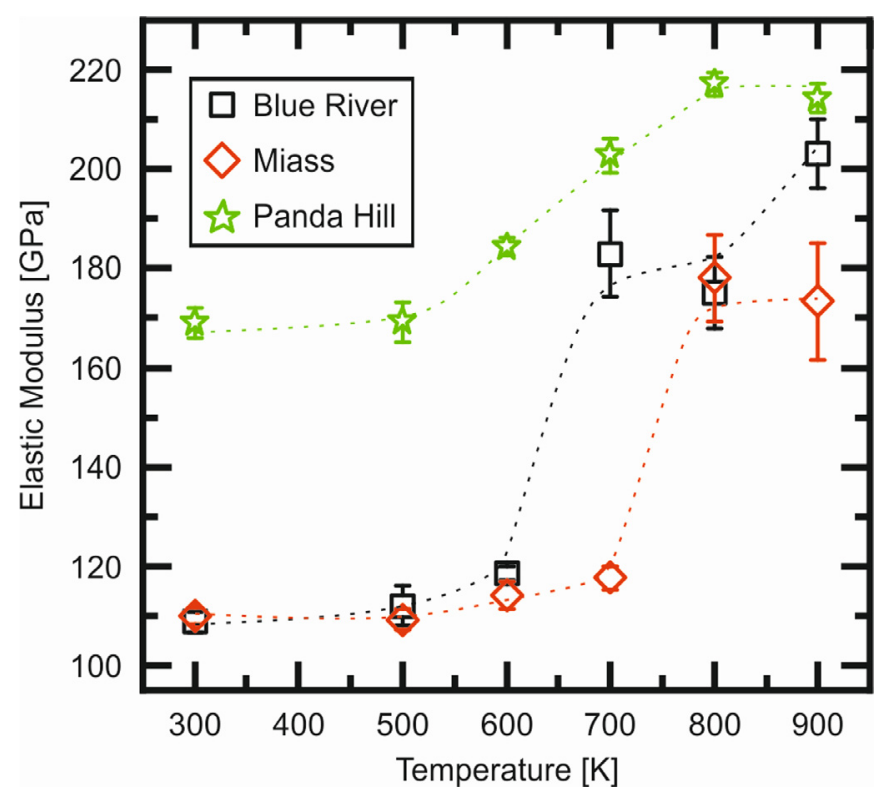

Fig. 3. Evolution of the average elastic modulus as a function of annealing temperature of pyrochlore samples Panda Hill (green stars), Blue River (black squares) and Miass (red diamonds). All measurements were obtained at room temperature. The lines are a guide for the eye. 
Table 2

Elastic modulus $(E)$ of pyrochlore samples Panda Hill, Blue River, and Miass after annealing at different temperature steps. All measurements were obtained at room temperature. The given values are averages of multiple measurements at indentation depths of 250-300 $\mathrm{nm}$.

\begin{tabular}{lllllll}
\hline Sample & Pristine & $500 \mathrm{~K}$ & $600 \mathrm{~K}$ & $700 \mathrm{~K}$ & $800 \mathrm{~K}$ & $900 \mathrm{~K}$ \\
\hline Panda Hill & $169.1 \pm 3.1$ & $169.2 \pm 4.0$ & $184.3 \pm 1.8$ & $202.8 \pm 3.5$ & $217.2 \pm 2.4$ & $214.3 \pm 3.0$ \\
Blue River & $108.8 \pm 2.1$ & $112.0 \pm 4.0$ & $118.7 \pm 1.4$ & $183.0 \pm 8.8$ & $175.2 \pm 7.2$ & $203.0 \pm 6.9$ \\
Miass & $109.9 \pm 1.7$ & $109.2 \pm 2.2$ & $114.1 \pm 2.8$ & $117.6 \pm 2.2$ & $178.1 \pm 8.7$ & $173.3 \pm 11.9$ \\
\hline
\end{tabular}

in hardness to $\sim 11.5 \mathrm{GPa}$ is visible, while the modulus changes barely (Tables 1,2, Figs. 2,3).

Pristine Blue River pyrochlore reveals a hardness of $\sim 7.4 \mathrm{GPa}$ and an elastic modulus of $\sim 109 \mathrm{GPa}$ (Tables 1,2, Figs. 2,3). Step-wise annealing of the Blue River sample up to $600 \mathrm{~K}$ indicates a very slightly increasing trend of $H$ and $E$ (Tables 1,2, Figs. 2,3). The sample undergoes a strong and relatively abrupt increase in hardness and elastic modulus after annealing at $700 \mathrm{~K}$ to $\sim 10.1 \mathrm{GPa}(+36 \%)$ and $\sim 183 \mathrm{GPa}(+68 \%)$, respectively. A second increase of the mechanical properties is visible after annealing at $900 \mathrm{~K}$, leading to a hardness of $\sim 11.6 \mathrm{GPa}(+15 \%)$ and elastic modulus of $\sim 203 \mathrm{GPa}(+11 \%)$.

The pristine Miass sample indicates a hardness of $\sim 7.5 \mathrm{GPa}$ and an elastic modulus of $\sim 110 \mathrm{GPa}$ (Tables 1,2, Figs. 2,3). Miass pyrochlore also shows a very slightly increasing trend of $H$ and $E$ up to stepwise annealing of $700 \mathrm{~K}$ (Tables 1,2, Figs. 2,3). Annealing at $800 \mathrm{~K}$ leads to a strong abrupt increase of $H$ and $E$ to $\sim 12.0 \mathrm{GPa}(+60 \%)$ and $\sim 178 \mathrm{GPa}$ $(+62 \%)$, respectively. After annealing at $900 \mathrm{~K}$ the hardness continues to increase to $\sim 13.3 \mathrm{GPa}(+11 \%)$, whereas the elastic modulus stays the same within the error $(\sim 173 \mathrm{GPa})$.

\subsection{Transmission electron microscopy}

Low magnification HAADF images of pristine Panda Hill, Blue River and Miass TEM specimens are shown in Fig. 4a,c and e, respectively. The Panda Hill sample consists of large crystalline (several microns in size) grains of pyrochlore as confirmed by selected area electron diffraction (SAED) pattern shown in Fig. 4b. The image was taken in [110] orientation. The phase identification is also supported by corresponding EDX analysis and verification of the space angle for the $F d \overline{3} m$ structure [57] by tilting to the [112] orientation (Fig. SI-1). In contrast, the lamellas prepared from the Blue River and Miass samples are mainly amorphous as evidenced by the corresponding SAED patterns (Fig. 4d,f). Crystalline grains of different sizes are found in the Blue River sample (Fig. 4c). Interestingly, all SAED patterns from Blue river specimens demonstrate the presence of regular spots corresponding to $\{220\}$ planes.

To track the structural changes of the highly disordered Blue River and Miass specimens during in-situ heating, dynamic conical dark field imaging was applied. This technique allows for the collection of images formed by electrons scattered by equivalent crystallographic planes in all azimuthal directions. These electrons form circles when a material has a polycrystalline structure. The scattering angle was limited by an objective aperture of $40 \mu \mathrm{m}$ in diameter (white circle in the Fig. 4d,f). Movie 1 shows the recrystallization of the Blue River specimen at $750 \mathrm{~K}$. One can observe changes of the contrast caused by recrystallization and of the orientation already after $\sim 4 \mathrm{~min}$. After $30 \mathrm{~min}$ the recrystallization is complete. According to subsequent low selected area diffraction and high-resolution imaging (Fig. 5a,b,c), in-situ heating results in a structure very similar to that of initially crystalline Panda Hill pyrochlore. The lamella transforms into a large single crystal grain. The annealed sample has also been characterized by HRTEM imaging and EDX spectroscopy. The lattice parameters of the recrystallized specimen slightly differ from the pyrochlore structure $(\sim 2-3 \%)$ and the amount of $\mathrm{F}$ and $\mathrm{O}$ is lower (Figure SI-2). In general, the loss of light elements is rather typical for in-situ heating in vacuum.
In contrast, in-situ heating of Miass pyrochlore, carried out with the same experimental parameters but at a slightly higher temperature of $\sim 800 \mathrm{~K}$ (Movie 2), leads to a polycrystalline structure (Fig. 5d,e). The grain size ranges from 10 to $50 \mathrm{~nm}$ (Fig. 5e). Again, the structure of the newly formed grains corresponds to the crystalline Miass pyrochlore with slightly $(\sim 3 \%)$ larger lattice parameters, which can be explained by lattice expansion due to the loss of $\mathrm{F}$ and $\mathrm{O}$ during in-situ heating in vacuum, an effect known as chemical expansion [58] (Fig. SI-3).

\subsection{Spectroscopy}

\subsubsection{Raman spectroscopy}

The measured Raman spectra of all three pyrochlores consist of relatively broad and overlapping modes, due to chemical and radiationinduced disorder [51,59]. An overall change in the intensity ratio $\left(\mathrm{I}_{605} / \mathrm{I}_{810}\right)$ between the prominent signals in the range of $605-680 \mathrm{~cm}^{-1}$ and of $810-860 \mathrm{~cm}^{-1}$ is visible with increasing annealing temperature (Fig. 6). The prominent spectral parts between $\sim 400-950 \mathrm{~cm}^{-1} \mathrm{com}-$ prise A-O (stretching), $\mathrm{B}-\mathrm{O}$ (stretching and bending) and $\mathrm{O}-\mathrm{B}-\mathrm{O}$ (bending) modes (assigned for pyrochlore phases by [60-62]). For possible mode assignments we refer to Zietlow et al. [51] and references therein.

Panda Hill pyrochlore indicates a sharpening of the lower-energy modes $\left(<330 \mathrm{~cm}^{-1}\right)$ and a noticeable increase in the $\mathrm{I}_{605} / \mathrm{I}_{810}$ ratio after annealing at $600 \mathrm{~K}$ (Fig. 6a). This trend continues with increasing temperature.

The pristine Blue River sample indicates some inhomogeneity, as areas with $\mathrm{I}_{605} / \mathrm{I}_{810}$ ratios below (absolute majority) and $\geq 1$ are detectable in the pristine sample (Fig. 6b). After annealing at $600 \mathrm{~K}$ the lowerenergy modes $\left(<330 \mathrm{~cm}^{-1}\right)$ sharpen and only spectra with $\mathrm{I}_{605} / \mathrm{I}_{810}>$ 1 are still detectable. Further, distinct modes between $\sim 720-850 \mathrm{~cm}^{-1}$ (assigned to U/Ta-O stretching modes by Zietlow et al. [51]) become sharper. This trend continues with annealing at $700 \mathrm{~K}$ where a distinct shoulder becomes visible at $\sim 765 \mathrm{~cm}^{-1}$.

Pristine Miass pyrochlore shows no distinct features in the lower energy mode region $\left(<330 \mathrm{~cm}^{-1}\right)$ and a general $\mathrm{I}_{605} / \mathrm{I}_{810}$ ratio below 1 (Fig. 6c). Annealing at $800 \mathrm{~K}$ leads to the formation of sharper signals below $330 \mathrm{~cm}^{-1}$ and a noticeable increase of $\mathrm{I}_{605} / \mathrm{I}_{810}$ exceeding 1 .

After the $800 \mathrm{~K}$ annealing-step the Raman spectra of all three samples look relatively similar, despite the sharp extra modes between $\sim 720$ $850 \mathrm{~cm}^{-1}$ that are only visible in Blue River pyrochlore.

\subsubsection{Photoluminescence spectroscopy}

The pristine Panda Hill and Miass samples show strong photoluminescence emissions with two distinct features in the region between $\sim 775$ and $950 \mathrm{~nm}$ (Fig. 7a,c). Whereas, in the pristine Blue River sample no signal can be detected (Fig. 7b), except at some very rare lesser disordered locations. Additionally, pristine Panda Hill pyrochlore already shows a relatively distinct feature around $\sim 925 \mathrm{~nm}$.

The Panda Hill sample reveals a first sharpening of the strong signal between $\sim 850$ and $950 \mathrm{~nm}$ after annealing at $600 \mathrm{~K}$ (Fig. 7a). The annealing step at $700 \mathrm{~K}$ causes a noticeable splitting of both initial features (between $\sim 775$ and $950 \mathrm{~nm}$, including the signal around $\sim 925 \mathrm{~nm}$ ) into several sharp distinct signals (Fig. 7a). Annealing at higher temperatures leads to further sharpening of the signals.

Annealing at $500 \mathrm{~K}$ leads in the Blue River sample to the occurrence of a weak, noisy and broad signal (Fig. 7b). After annealing at $600 \mathrm{~K}$, 
Panda Hill
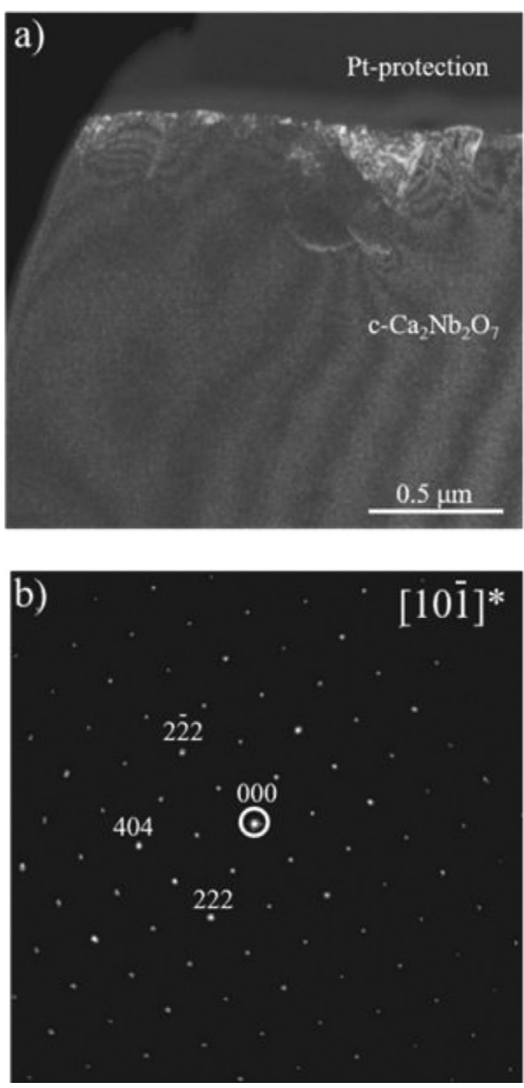

Blue River
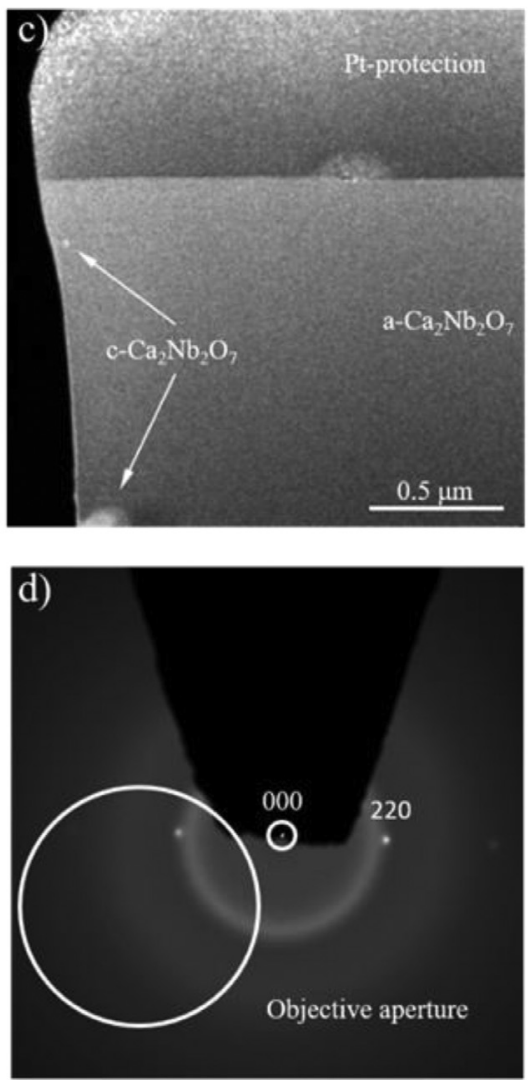

Miass
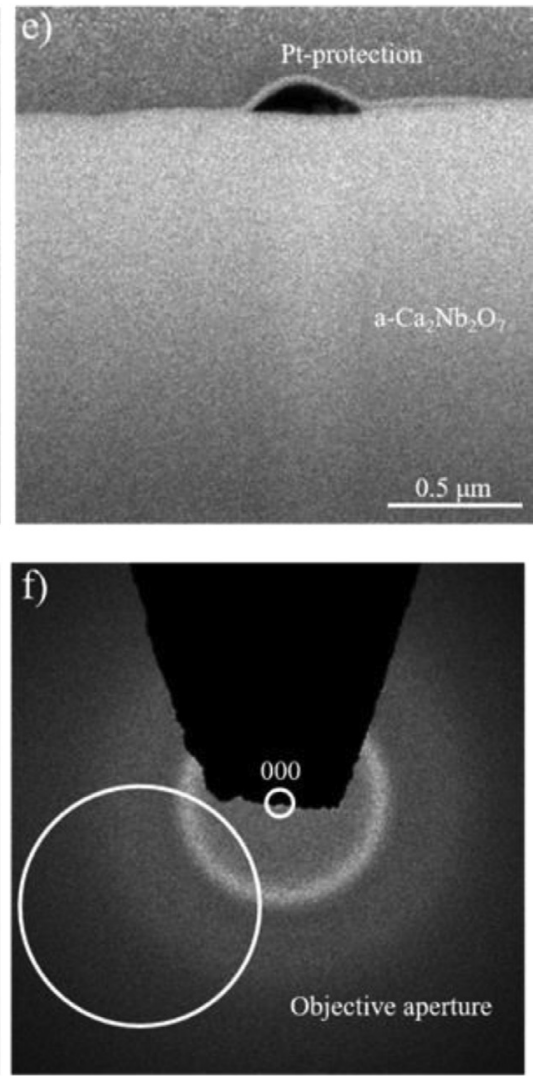

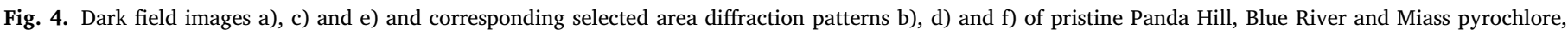

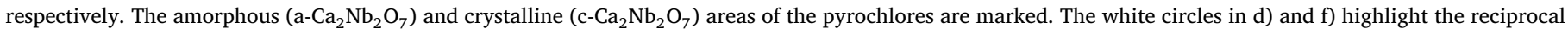
space to form the dark field images.

also in this sample, two distinct features in the region between $\sim 775$ and $950 \mathrm{~nm}$ become clearly visible. The signal between $\sim 775-850 \mathrm{~nm}$ shows a maximum around $\sim 810 \mathrm{~nm}$, while the stronger one (between $\sim 850$ - $950 \mathrm{~nm}$ ) indicates a sharp maximum around $\sim 880 \mathrm{~nm}$. Step-wise annealing at $700 \mathrm{~K}$ and higher leads to splitting and further sharpening of the latter main signal. Additionally, a distinct feature around $\sim 925 \mathrm{~nm}$ occurs.

The pristine Miass photoluminescence spectrum is comparable to that of Blue River after annealing at $600 \mathrm{~K}$. Two distinct features in the region between $\sim 775$ and $950 \mathrm{~nm}$ are visible with maxima around $\sim 810$ and $\sim 880 \mathrm{~nm}$, respectively (Fig. $7 \mathrm{c}$ ). Annealing at 800 and $900 \mathrm{~K}$ causes signal splitting and sharpening. Further, a distinct feature around $\sim 925 \mathrm{~nm}$ becomes visible.

\section{Discussion}

\subsection{Pristine radiation-damaged pyrochlore}

The pristine Panda Hill sample shows the highest hardness $(H)$ and elastic modulus $(E)$ of the investigated samples (Tables 1,2, Figs. 2,3). While the pristine Blue River and Miass samples, revealing similar mechanical properties, are much softer and more compliant. This is in good agreement with the TEM measurements, indicating a high degree of structural order for Panda Hill and a high degree of disorder for Blue River and Miass pyrochlore (Fig. 4). Zietlow et al. [51] report Panda Hill pyrochlore to be only weakly damaged, Blue River to be highly disordered with preserved crystalline domains and Miass to be completely $\mathrm{X}$-ray amorphous. Hence, at high degrees of amorphization the disorder related mechanical softening can be expected to saturate.
The observed strong broadening of the Raman and photoluminescence signals (the latter attributed to the emission of $\mathrm{Nd}^{3+}$ [63]) indicates the disturbed short-range order due to radiation-damage and impurities in all samples (Figs. 6,7). Further, our Raman spectroscopic investigations confirm the already assumed inhomogeneous amorphization of Blue River pyrochlore [51]. Some areas of the pristine sample reveal spectra indicative of a higher degree of short-range order $\left(\mathrm{I}_{605} / \mathrm{I}_{810}\right.$ $\geq 1$ ) (Fig. 6b). These higher ordered domains are also visible in the TEM measurements of Blue River. The $\{220\}$ planes in Blue River pyrochlore (occupied mainly by $\mathrm{Nb}$ and $\mathrm{Ca}$ ) seem to be relatively steady during structural damage. The combination of the overall strong structural disorder and the very low Nd content (below the detection limit) leads most likely to the undetectable or very weak and noisy photoluminescence signal in the pristine Blue River sample and after annealing at $500 \mathrm{~K}$ (Fig. 7b).

\subsection{Effect of thermal annealing}

In this study, we performed long term annealing of the pyrochlore samples for $16 \mathrm{~h}$ at each temperature step to ensure a saturation of the thermally induced structural reorganization effect. The results are in good agreement with earlier powder XRD measurements (step-wise short term annealing of $1 \mathrm{~h}$ ) (Zietlow et al. [51]) of these samples. The mechanical properties of the crystalline but partially disturbed Panda Hill sample start to increase after annealing at $600 \mathrm{~K}$ (Tables 1,2, Figs. 2,3). This is due to the healing of defects (e.g., vacancies, interstitials, etc.) and structural reorganization, increasing the overall connectivity and bond strength of the material. The beginning of the band sharpening observed in the spectroscopic data (Figs. 6,7) confirms the onset of the increasing short-range order (e.g., reduction of defects, 

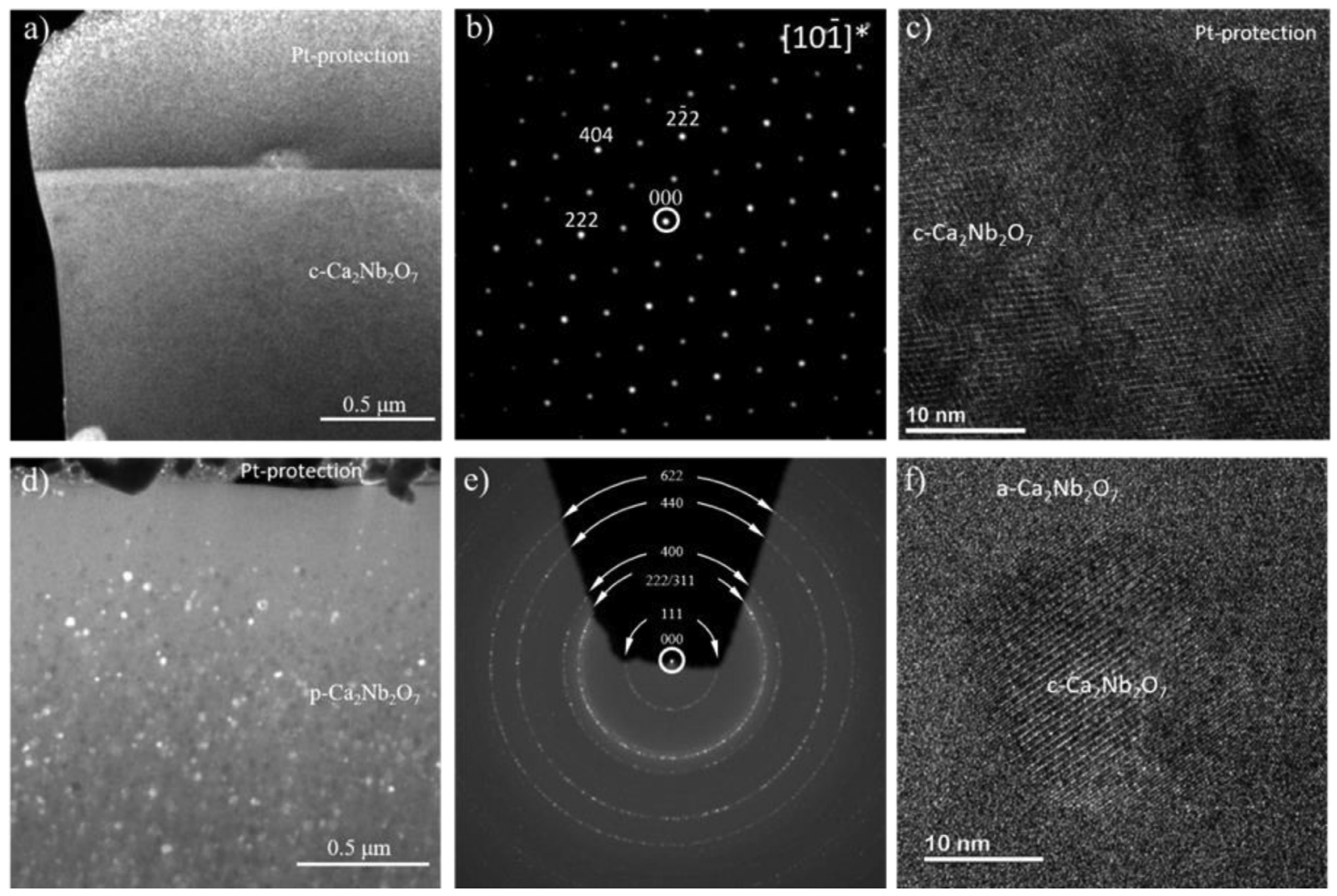

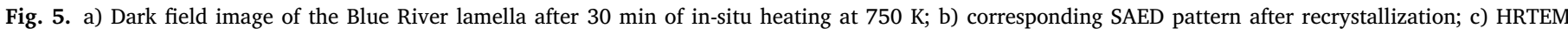

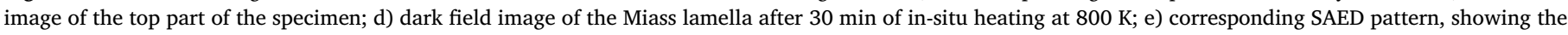

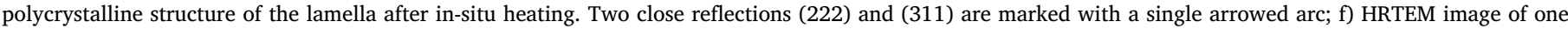
in-situ formed pyrochlore grain.

reestablishment of bonds and polyhedra assemblies) at this temperature. The long-range order has also been found to increase at temperatures above $500 \mathrm{~K}$ [51].

According to the results of the spectroscopic measurements, the $600 \mathrm{~K}$ annealing step is sufficient to increase the crystalline order in the originally highly disordered parts of the Blue River sample (Figs. 6,7). Also powder X-ray diffraction (PXRD) shows a slight decrease of the amorphous fraction after this annealing step [51].

The most prominent structural reorganization takes place in the highly disordered Blue River sample that contains small preserved crystalline domains, after annealing at $700 \mathrm{~K}$, leading to the observed huge increase of the mechanical properties (Tables 1,2, Figs. 2,3). The sharpening and splitting of the corresponding photoluminescence and Raman signals confirm the increase in short-range order. While PXRD also indicates an increase in the correlation length at the $700 \mathrm{~K}$ annealing step [51]. One can think of preserved crystalline domains as acting as seed crystals, accelerating the recrystallization process. In-situ TEM measurements obtained at $750 \mathrm{~K}$ indicate a relatively rapid recrystallization process at this annealing temperature and reveal the reestablishment of a single crystal (Fig. 5a-c, Movie 1).

While the Panda Hill pyrochlore shows further gradual increase in structural order up to annealing at $800 \mathrm{~K}$, which hardens the mechanical properties, the X-ray amorphous Miass sample undergoes an abrupt strong increase in crystallinity at this temperature step. This is indicated by a strong raise in $H$ and $E$ (Tables 1,2, Figs. 2,3) and a noticeable change in the spectroscopic data (Fig. 6,7). The obvious increase in the Raman $\mathrm{I}_{605} / \mathrm{I}_{810}$ ratio is indicative for local ordering. The increase in long-range order at the $800 \mathrm{~K}$ annealing step is confirmed by in-situ TEM (Fig. 5d-f, Movie 2) and PXRD [51]. The corresponding SAED pattern of the annealed Miass sample indicates a resulting polycrystalline structure that can explain the higher hardness, due to grain boundaries, compared to the Blue River single crystal (Table 1, Figs. 2,9). From $800 \mathrm{~K}$ annealing on the Raman spectra of all three samples look relatively similar, indicating a comparable degree of short range order (Fig. 6). Raman spectroscopy indicates local ordering around the A and B positions. The former is additionally confirmed by photoluminescence spectroscopy (as most of the $\mathrm{Nd}$ is expected to be located on the A position).

Further step-wise annealing up to $900 \mathrm{~K}$ of Blue River pyrochlore shows the formation of a plateau in the increasing trend of the mechanical properties (Tables 1,2, Figs. 2,3). This is also visible in the evolution of the PXRD data of this sample that indicates the increasing correlation length with increasing temperature [51]. We expect this to be related to inhomogeneous recrystallization in the sample (leading also to the observed larger error in average $H$ and $E$ ), indicating that higher temperatures are needed to establish further homogeneity and order.

Crystalline Panda Hill pyrochlore shows a decrease in $H$ after annealing at $900 \mathrm{~K}$ (Tables 1,2, Figs. 2,3), while the modulus does not change noticeably. A possible explanation is the observed release of structural fluorine (beginning around $890 \mathrm{~K}$ ), as indicated by mass spectrometry (Fig. 8). One might think of fluorine incorporated on the $\mathrm{Y}$ position (Fig. 1) acting from mechanical point of view as some kind of defect. This effect may be masked in Blue River by the ongoing recrystallization (nevertheless it reaches the same $H$ as Panda Hill) and in Miass by the occurrence of a new phase, both effecting strongly the mechanical properties. Zietlow et al. [51] reported the occurrence of a $\mathrm{NaNbO}_{3}$ phase in Miass pyrochlore at annealing temperatures around $820 \mathrm{~K}$ that can cause the observed stagnation of the elastic modulus after annealing at $900 \mathrm{~K}$ (Table 2, Fig. 3).

Further, the thermally induced structural reordering of Blue River and Miass pyrochlore was found to occur not smoothly but via 


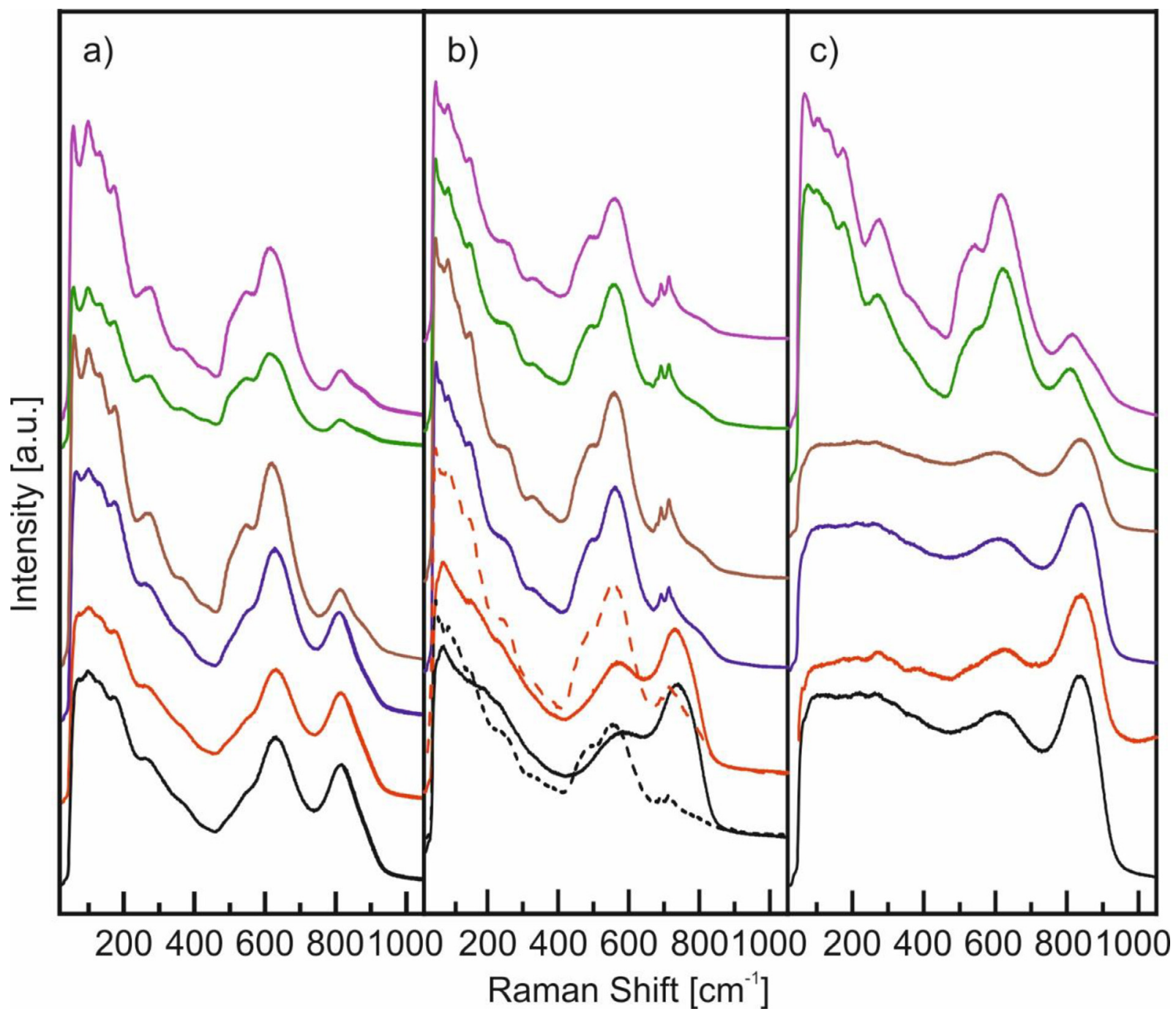

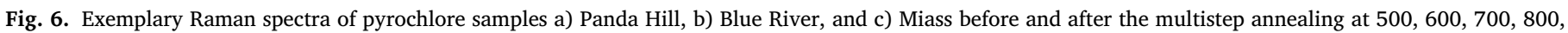
and $900 \mathrm{~K}$ (from bottom to top). Already at RT some higher ordered regions appeared (dashed spectra). All measurements were obtained at room temperature.

avalanches [64]. Hence, the recrystallization phase fronts move by local singularities, as the system relaxes from the unstable to a stable situation via sequences of metastable states, driven by thermal energy over time. The related jumps to the next local minima (each time the energy barrier disappears) are masked as the resolution of the temperature steps in this study is far too low. Nevertheless, one can expect the plateau-like behavior visible in the evolution of the elastic modulus in Blue River (between 700 and $800 \mathrm{~K}$ step) and in Miass (between 800 and $900 \mathrm{~K}$ step) to show also contributions from a larger energy barrier. A strong jerky behavior is observed in these temperature regions [64].

The similarity of the mechanical properties of samples Panda Hill and Blue River after annealing at $900 \mathrm{~K}$ (Tables 1,2, Figs. 2,3,9) is in excellent agreement with their proposed comparable high degree of structural order [51]. The in general gradual and smaller increase in hardness and elastic modulus of the Panda Hill sample in comparison with Blue River and Miass (Tables 1,2, Figs. 2,3) is assumed to be related to the already initially high degree of crystallinity.

An overall comparable (but in the investigated temperature region less pronounced) recrystallization related mechanical hardening has been revealed for the $\mathrm{U}$ and/or Th containing radiation-damaged minerals allanite $\left[(\mathrm{Ca})(\mathrm{REE})(\mathrm{Al})_{2}\left(\mathrm{Fe}^{2+}\right)\left[\mathrm{SiO}_{4}\right]\left[\mathrm{Si}_{2} \mathrm{O}_{7}\right] \mathrm{O}(\mathrm{OH})\right][65]$ and at higher temperatures also titanite $\left(\mathrm{CaTiSiO}_{5}\right)[66]$. Although, initial me- chanical softening, as found in titanite $[66,67]$, has not been observed in pyrochlore.

\section{Summary and conclusion}

In summary, mechanical properties were found to be sensitive indicators of the thermally induced structural reorganization process in radiation-damaged pyrochlore. Together with TEM and spectroscopy a comprehensive picture of the global and short-range order was obtained. The mechanical measurements confirm that the bulk annealing kinetics directly depend on the initial degree and homogeneity of the structural damage (visible especially in the elastic modulus behavior, providing a measure for the general interconnectivity). The energy exponent related assumption that small regions recrystallize more often than large regions [64] also agrees with the results. The structural reorganization in general was found to start above $500 \mathrm{~K}$ in these pyrochlores (this study and [51]), which demarks the upper limit of the temperatures reported to occur in a repository [68]. Our observation that highly radiation-damaged Miass pyrochlore reaches a polycrystalline state after annealing with highest hardness of both investigated heavily damaged samples (i.e., compared to Blue River) should be relevant to long-term encapsulation of actinides. 


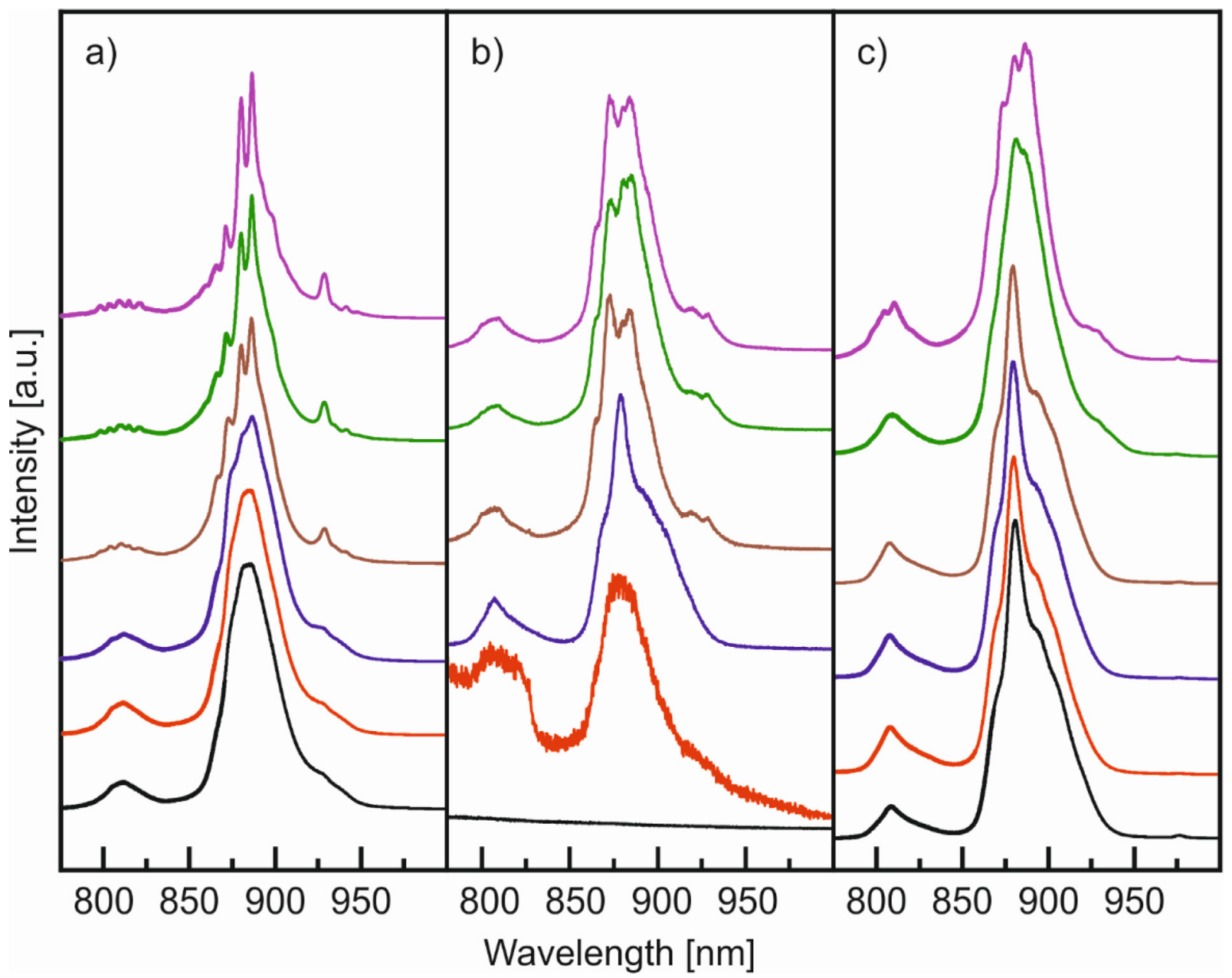

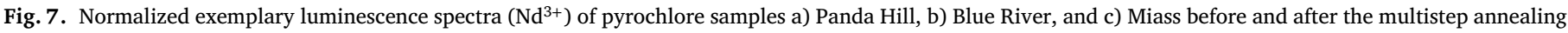
at $500,600,700,800$, and $900 \mathrm{~K}$ (from bottom to top). All measurements were obtained at room temperature.

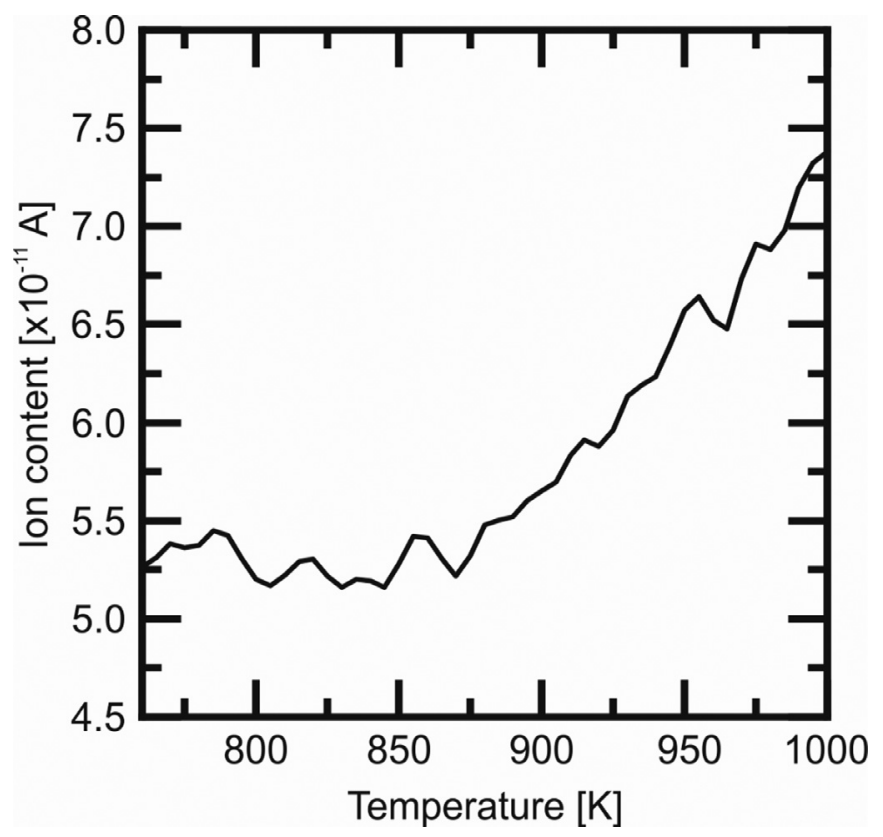

Fig. 8. Mass spectrometric analysis of Panda Hill pyrochlore during annealing $(10 \mathrm{~K} / \mathrm{min}$ ) in synthetic air (mass is assigned to 19: fluorine).

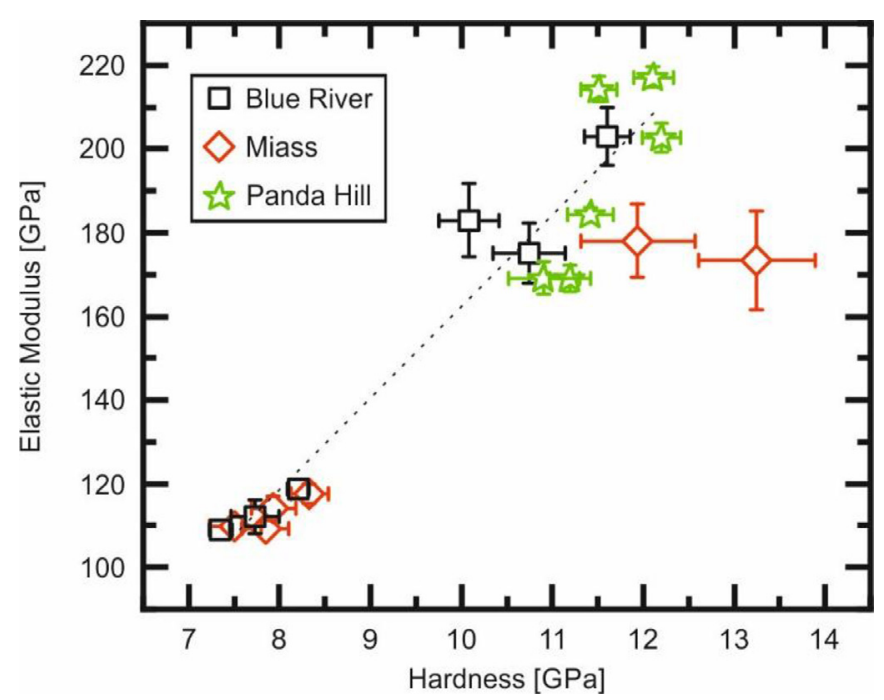

Fig. 9. Elastic modulus as a function of hardness for pyrochlore samples Panda Hill (green stars), Blue River (black squares) and Miass (red diamonds), before and after annealing at various temperature steps (see Tables 1,2). All measurements were obtained at room temperature. The dotted line is a guide for the eye. 
The elastic modulus as a function of hardness of all three samples before and after each annealing step indicates a general increasing linear trend with increasing structural order (Fig. 9). Three regimes are visible: A distinct low $E$ and $H$ region ( $\sim 105-121 \mathrm{GPa}$ and $\sim 7.2-8.6 \mathrm{GPa}$, respectively), comprising the highly disordered states. Further, a crystalline (but partially disturbed) area in a relatively distinct modulus region ( 165-192 GPa), providing evidence for a comparable degree of reestablished bonds and increased bond strength. The hardness range shows a broader scatter, caused by the initially X-ray amorphous Miass sample ( $\sim 9.7-13.9 \mathrm{GPa})$, that can be related to the effect of additional grain boundaries. The third regime comprises highly crystalline pyrochlore ( $\sim 198-220 \mathrm{GPa}$ and $\sim 11.3-12.4 \mathrm{GPa}$, respectively). Although, Miass pyrochlore further recrystallizes, its polycrystalline structure and the additional formed phase are expected to prevent the modulus from entering this state. These regimes are in excellent agreement with the varying shapes of the photoluminescence spectra, indicating a comparable local order. Additionally, the varying average amorphous fractions of these samples [51] coincide very well with this classification.

\section{Declaration of Competing Interest}

The authors declare that they have no known competing financial interests or personal relationships that could have appeared to influence the work reported in this paper.

\section{Acknowledgments}

This research was funded by the Deutsche Forschungsgemeinschaft (DFG, German Research Foundation) - BE 5456/2-1 (T.B. and C.E.R.). We thank Thomas Malcherek for sample orientation, Peter Stutz for sample preparation, and the Pacific Museum of Earth (University of British Columbia), the Centrum für Naturkunde - Mineralogical Museum Hamburg and Thomas Chudy for sample material. We thank David Dempsey (University of Auckland) for proofreading the manuscript. The valuable comments of an anonymous reviewer are gratefully acknowledged.

\section{Supplementary materials}

Supplementary material associated with this article can be found, in the online version, at doi:10.1016/j.mtla.2020.100950.

\section{References}

[1] Y. Yasui, M. Soda, S. Iikubo, M. Ito, M. Sato, N. Hamaguchi, T. Matsushita, N. Wada, T. Takeuchi, N. Aso, K. Kakurai, Ferromagnetic transition of pyrochlore compound $\mathrm{Yb}_{2} \mathrm{Ti}_{2} \mathrm{O}_{7}$, J. Phys. Soc. Jpn. 72 (2003) 3014-3015, doi:10.1143/jpsj.72.3014.

[2] R.C. Ewing, W.J. Weber, J. Lian, Nuclear waste disposal-pyrochlore $\left(\mathrm{A}_{2} \mathrm{~B}_{2} \mathrm{O}_{7}\right)$ : nuclear waste form for the immobilization of plutonium and "minor" actinides, J. Appl. Phys. 95 (2004) 5949-5971, doi:10.1063/1.1707213.

[3] J. Cheng, J. Li, C. Ma, Z. Hao, Catalytic combustion of methane over $\mathrm{La}_{2} \mathrm{TM}_{0.3} \mathrm{Zr}_{1.7} \mathrm{O}_{7-\delta}(\mathrm{TM}=\mathrm{Mn}, \mathrm{Fe}$, and $\mathrm{Co}$ ) pyrochlore oxides, Catal. Commun. 10 (2009) 1170-1173, doi:10.1016/j.catcom.2009.01.006.

[4] K. Matsushira, M. Tokunaga, M. Wakeshima, Y. Hinatsu, S. Takagi, Giant magnetoresistance effect in the metal-insulator transition of pyrochlore oxide $\mathrm{ND}_{2} \mathrm{Ir}_{2} \mathrm{O}_{7}, \mathrm{~J}$. Phys. Soc. Jpn. 82 (2013) 023706, doi:10.7566/JPSJ.82.023706.

[5] E. Öztürk, E. Sarlmaz, Investigation of photoluminescence and piezoelectric behavior of the multifunctional $\mathrm{Eu}_{2} \mathrm{Ti}_{2} \mathrm{O}_{7}$ pyrochlore doped with $\mathrm{In}^{3+}$ and $\mathrm{Sb}^{3+}$, Mater. Res. Express 6 (2019) 105710, doi:10.1088/2053-1591/ab3e21.

[6] A.A. Digeos, J.A. Valdez, K.E. Sickafus, A.R. Boccaccini, S. Atiq, R.W. Grimes, Glass matrix/pyrochlore phase composites for nuclear wastes encapsulation, J. Mater. Sci. 38 (2003) 1597-1604, doi:10.1023/A:1023242702644.

[7] M. Jafar, P. Sengupta, S.N. Achary, A.K. Tyagi, Phase evolution and microstructural studies in $\mathrm{CaZrTi}_{2} \mathrm{O}_{7}$ (zirconolite)- $\mathrm{Sm}_{2} \mathrm{Ti}_{2} \mathrm{O}_{7}$ (pyrochlore) system, J. Eur. Ceram. Soc. 34 (2014) 4373-4381, doi:10.1016/j.jeurceramsoc.2014.07.001.

[8] R.C. Ewing, Nuclear waste forms for actinides, Proc. Natl. Acad. Sci. USA 96 (1999) 3432-3439, doi:10.1073/pnas.96.7.3432.

[9] Y. Zhang, K.P. Hart, W.L. Nourcier, R.A. Day, M. Colella, B. Thomas, Z. Aly, A. Jostsons, Kinetics of uranium release from Synroc phases, J. Nucl. Mater. 289 (2001) 254-262, doi:10.1016/S0022-3115(01)00423-8.

[10] G.R. Lumpkin, R.C. Ewing, C.T. Williams, A.N. Mariano, An overview of the crystal chemistry, durability, and radiation damage effects of natural pyrochlore, Mater. Res. Soc. Symp. Proc. 663 (2001) 921, doi:10.1557/PROC-663-921.
[11] H. Xu, Y. Wang, P. Zhao, W.L. Bourcier, R. Van Konynenburg, H.F. Shaw, Investigation of pyrochlore-based u-bearing ceramic nuclear waste: uranium leaching test and TEM observation, Environ. Sci. Technol. 38 (2004) 1480-1486, doi:10.1021/es030582v.

[12] W.J. Weber, A. Navrotsky, S. Stefanovsky, E.R. Vance, E. Vernaz, Materials science of high-level nuclear waste immobilization, MRS Bull. 34 (2009) 46-53, doi:10.1557/mrs2009.12.

[13] Y. Zhang, Z. Zhang, G. Thorogood, E.R. Vance, Pyrochlore based glass-ceramics for the immobilization of actinide-rich nuclear wastes. From concept to reality, J. Nucl. Mater. 432 (2013) 545-547, doi:10.1016/j.jnucmat.2012.08.035.

[14] G.R. Lumpkin, Y. Gao, R. Gieré, C.T. Williams, A. Mariano, T. Geisler, The role of Th-U minerals in assessing the performance of nuclear waste forms, Mineral. Mag. 78 (2014) 1071-1095, doi:10.1180/minmag.2014.078.5.01.

[15] Z. Tang, Z. Huang, W. Han, J. Qi, Y. Shi, N. Ma, Y. Zhang, X. Guo, T. Lu, Uranium-incorporated pyrochlore $\mathrm{La}\left(\mathrm{U}_{\mathrm{x}} \mathrm{Mg}_{\mathrm{x}} \mathrm{Zr}_{1-2 \mathrm{x}}\right)_{2} \mathrm{O}_{7}$ nuclear waste form: structure and phase stability, Inorg. Chem. 59 (2020) 9919-9926, doi:10.1021/acs.inorgchem.0c01089.

[16] K. Wu, F. Fang, Q. Liao, H. Zhu, D. Liu, Y. Zhu, Synthesis of pyrochlore-borosilicate glass-ceramics for immobilization of high-level nuclear waste, Ceram. Int. 46 (2020) 6085-6094, doi:10.1016/j.ceramint.2019.11.071.

[17] D.M. Strachan, R.D. Scheele, E.C. Buck, A.E. Kozelisky, R.L. Sell, R.J. Elovich, W.C. Buchmiller, Radiation damage effects in candidate titanates for Pu disposition: zirconolite, J. Nucl. Mater. 345 (2005) 109-135, doi:10.1016/j.jnucmat.2005.04.064.

[18] B.C. Chakoumakos, R.C. Ewing, Crystal chemical constraints on the formation of actinides pyrochlores, MRS Proc. 44 (1985) 641, doi:10.1557/PROC-44-641.

[19] B.C. Chakoumakos, Systematics of the pyrochlore structure type, ideal $A_{2} B_{2} X_{6} Y, J$. Solid State Chem. 53 (1984) 120-129, doi:10.1016/0022-4596(84)90234-2.

[20] D.D. Hogarth, C.T. Williams, P. Jones, Primary zoning in pyrochlore group minerals from carbonatites, Mineral. Mag. 64 (2000) 683-697, doi:10.1180/002646100549544.

[21] M. Glerup, O.F. Nielsen, F.W. Poulsen, The structural transformation from the pyrochlore structure, $\mathrm{A}_{2} \mathrm{~B}_{2} \mathrm{O}_{7}$, to the fluorite structure, $\mathrm{AO}_{2}$, studied by Raman spectroscopy and defect chemistry modeling, J. Solid State Chem 160 (2001) 25-32, doi:10.1006/jssc.2000.9142.

[22] D. Atencio, M.B. Andrade, A.G. Christy, R. Gieré, P.M. Kartashov, The pyrochlore supergroup of minerals: nomenclature, Can. Miner. 48 (2010) 673-698, doi:10.3749/canmin.48.3.673.

[23] G. Perrault, La composition shimique et la structure crystalline du pyrochlore d'Oka, P.Q., Can. Miner. 9 (1968) 383-402.

[24] R.C. Ewing, A. Meldrum, L.M. Wang, S.X. Wang, Radiation-induced amorphization, Rev. Mineral. Geochem. 39 (2000) 319-361, doi:10.2138/rmg.2000.39.12.

[25] R.C. Ewing, Actinides and radiation effects: impact on the back-end of the nuclear fuel cycle, Mineral. Mag. 75 (2011) 2359-2377, doi:10.1180/minmag.2011.075.4.2359.

[26] G.R. Lumpkin, R.C. Ewing, Y. Eyal, Preferential leaching and natural annealing of alpha-recoil tracks in metamict betafite and samarskite, J. Mater. Res. 3 (1988) 357368, doi:10.1557/JMR.1988.0357.

[27] G.R. Lumpkin, R.C. Ewing, Alpha-decay damage in minerals of the pyrochlore group Phys. Chem. Miner. 16 (1988) 2-20, doi:10.1007/BF00201325.

[28] G.R. Lumpkin, Alpha-decay damage and aqueous durability of actinide host phases in natural systems, J. Nucl. Mater. 289 (2001) 136-166, doi:10.1016/S0022-3115(00)00693-0.

[29] R.C. Ewing, B.C. Chakoumakos, G.R. Lumpkin, T. Murakami, R.B. Greegor, F.W. Lytle, Metamict minerals: natural analogues for radiation damage effects in ceramic nuclear waste forms, Nucl. Instrum. Methods B 32 (1988) 487-497, doi:10.1016/0168-583X(88)90259-5.

[30] R.C. Ewing, W.J. Weber, F.W. Clinard Jr., Radiation effects in nuclear waste forms for high-level radioactive waste, Prog. Nucl. Energy 29 (1995) 63-127, doi:10.1016/0149-1970(94)00016-Y.

[31] R.C. Ewing, Displaced by radiation, Nature 445 (2007) 161-162, doi:10.1038/445161a

[32] E.K.H. Salje, J. Chrosch, R.C. Ewing, Is "metamictization" of zircon a phase transition? Am. Miner. 84 (1999) 1107-1116, doi:10.2138/am-1999-7-813.

[33] G.R. Lumpkin, R.C. Ewing, Alpha-decay damage and annealing effects in natural pyrochlores: analogues for long-term radiation damage effects in actinide, pyrochlore, structure types, MRS Proc. 127 (1989) 253-260, doi:10.1557/PROC-127-253.

[34] G.R. Lumpkin, R.C. Ewing, Geochemical alteration of pyrochlore group minerals: pyrochlore subgroup, Am. Miner. 80 (1995) 732-743, doi:10.2138/am-1995-7-814.

[35] G.R. Lumpkin, K.P. Hart, P.J. McGlinn, T.E. Payne, R. Gieré, C.T. Williams, Retention of actinides in natural pyrochlores and zirconolites, Radiochim. Acta 66/67 (1994) 469-474, doi:10.1524/ract.1994.6667.special-issue.469.

[36] G.R. Lumpkin, E.M. Foltyn, R.C. Ewing, Thermal recrystallization of alpha-recoil damaged minerals of the pyrochlore structure type, J. Nucl. Mater. 139 (1986) 113120, doi:10.1016/0022-3115(86)90029-2.

[37] M. Lang, F. Zhang, J. Zhang, J. Wang, J. Lian, W.J. Weber, B. Schuster, C. Trautmann, R. Neumann, R.C. Ewing, Review of $\mathrm{A}_{2} \mathrm{~B}_{2} \mathrm{O}_{7}$ pyrochlore response to irradiation and pressure, Nucl. Instrum. Methods B 268 (2010) 2951-2959, doi:10.1016/j.nimb.2010.05.016.

[38] M. Lang, M. Toulemonde, J. Zhang, F. Zhang, C.L. Tracy, J. Lian, Z. Wang, W.J. Weber, D. Severin, M. Bender, C. Trautmann, R.C. Ewing, Swift heavy ion track formation in $\mathrm{Gd}_{2} \mathrm{Zr}_{2-\mathrm{x}} \mathrm{Ti}_{\mathrm{x}} \mathrm{O}_{7}$ pyrochlore: effect of electronic energy loss, Nucl. Instrum. Methods B 336 (2014) 102-115, doi:10.1016/j.nimb.2014.06.019.

[39] J. Shamblin, C.L. Tracy, R.C. Ewing, F. Zhang, W. Li, C. Trautmann, M. Lang, Structural response of titanate pyrochlorest o swift heavy ion irradiation, Acta Mater. 117 (2016) 207-215, doi:10.1016/j.actamat.2016.07.017. 
[40] J. Shamblin, C.L. Tracy, R.I. Palomares, E. O'Quinn, R.C. Ewing, J. Neuefeind, M. Feygenson, J. Behrens, C. Trautmann, M. Lang, Similar local order in disordered fluorite and aperiodic pyrochlore structures, Acta Mater. 144 (2018) 60-67, doi:10.1016/j.actamat.2017.10.044.

[41] C.L. Tracy, J. Shamblin, S. Park, F. Zhang, C. Trautmann, M. Lang, R.C. Ewing, Role of composition, bond covalency, and short-range order in the disordering of stannate pyrochlores by swift heavy ion irradiation, Phys. Rev. B 94 (2016) 064102, doi:10.1103/PhysRevB.94.064102.

[42] F.X. Zhang, M. Lang, Z. Liu, R.C. Ewing, Pressure-induced disordering and anomalous lattice expansion in $\mathrm{La}_{2} \mathrm{Zr}_{2} \mathrm{O}_{7}$ pyrochlore, Phys. Rev. Lett. 105 (2010) 015503, doi:10.1103/PhysRevLett.105.015503.

[43] S. Park, M. Lang, C.L. Tracy, J. Zhang, F. Zhang, C. Trautmann, M.D. Rodriguez, P. Kluth, R.C. Ewing, Response of $\mathrm{Gd}_{2} \mathrm{Ti}_{2} \mathrm{O}_{7}$ and $\mathrm{La}_{2} \mathrm{Ti}_{2} \mathrm{O}_{7}$ to swift-heavy ion irradiation and annealing, Acta Mater. 93 (2015) 1-11, doi:10.1016/j.actamat.2015.04.010.

[44] C.-.K. Chung, J. Shamblin, E. O’Quinn, A. Shelyug, I. Gussev, M. Lang, A. Navrotsky, Thermodynamic and structural evolution of $\mathrm{Dy}_{2} \mathrm{Ti}_{2} \mathrm{O}_{7}$ pyrochlore after swift heavy ion irradiation, Acta Mater. 14 (2018) 227-234, doi:10.1016/j.actamat.2017.12.044.

[45] C.-.K. Chung, M. Lang, H. Xu, A. Navrotsky, Thermodynamics of radiation induced amorphization and thermal annealing of $\mathrm{Dy}_{2} \mathrm{Sn}_{2} \mathrm{O}_{7}$ pyrochlore, Acta Mater. 155 (2018) 386-392, doi:10.1016/j.actamat.2018.06.003.

[46] C.-.K. Chung, E. O'Quinn, J.C. Neiefeind, A.F. Fuentes, H. Xu, M. Lang, A. Navrotsky, Thermodynamic and structural evolution of mechanically milled and swift heavy ion irradiated $\mathrm{Er}_{2} \mathrm{Ti}_{2} \mathrm{O}_{7}$ pyrochlore, Acta Mater. 181 (2019) 309-317, doi:10.1016/j.actamat.2019.09.022.

[47] J. Lian, K.B. Helean, B.J. Kennedy, L.M. Wang, A. Navrotsky, R.C. Ewing, The orderdisorder transition in ion-irradiated pyrochlore, Acta Mater. 51 (2003) 1493-1502, doi:10.1016/S1359-6454(02)00544-X.

[48] Y. Xia, D. Yang, C.-.H. Chen, Y. Hao, R.C. Ewing, Y. Li, Structural evolution of $\mathrm{Lu}_{2-\mathrm{x}} \mathrm{Ce}_{\mathrm{x}} \mathrm{Ti}_{2} \mathrm{O}_{7}$ pyrochlores under 400keV Ne irradiation, J. Am. Ceram. Soc. 00 (2020) 1-11, doi:10.1111/jace.17290.

[49] M.T. Janish, M.M. Schneider, J.A. Valdez, K.J. McClellan, D.D. Byler, Y. Wang, D. Chen, T.G. Holesinger, B.P. Uberuaga, In-situ re-crystallization of heavily-irradiated $\mathrm{Gd}_{2} \mathrm{Ti}_{2} \mathrm{O}_{7}$, Acta Mater. 194 (2020) 403-411, doi:10.1016/j.actamat.2020.04.026.

[50] W.J. Weber, J.W. Wald, Hj. Matze, Effects of self-radiation damage in Cmdoped $\mathrm{Gd}_{2} \mathrm{Ti}_{2} \mathrm{O}_{7}$ and $\mathrm{CaZr} \mathrm{Ti}_{2} \mathrm{O}_{7}$, J. Nucl. Mater. 138 (1986) 196-209, doi:10.1016/0022-3115(86)90006-1.

[51] P. Zietlow, T. Beirau, B. Mihailova, L.A. Groat, T. Chudy, A. Shelyug, A. Navrotsky, R.C. Ewing, J. Schlüter, R. Škoda, U. Bismayer, Thermal annealing of natural, radiation-damaged pyrochlore, Z. Kristallogr. 232 (2017) 25-38, doi:10.1515/zkri-2016-1965.

[52] X. Li, B. Bhushan, A review of nanoindentation continuous stiffness measurement technique and its applications, Mater. Charact. 48 (2002) 11-36, doi:10.1016/S1044-5803(02)00192-4.

[53] W.C. Oliver, G.M. Pharr, Measurement of hardness and elastic modulus by instrument indentation: advances in understanding and refinements to methodology, J. Mater. Res. 19 (2004) 3-20, doi:10.1557/jmr.2004.19.1.3.
[54] W.C. Oliver, G.M. Pharr, An improved technique for determining hardness and elastic modulus using load and displacement sensing indentation experiments, J. Mater. Res. 7 (1992) 1564-1583, doi:10.1557/JMR.1992.1564.

[55] D.L. Joslin, W.C. Oliver, A new method for analyzing data from continuous depth-sensing microindentation tests, J. Mater. Res. 5 (1990) 123-126, doi:10.1557/JMR.1990.0123.

[56] I.N. Sneddon, The relation between load and penetration in the axisymmetric boussinesq problem for a punch of arbitrary profile, Int. J. Eng. Sci. 3 (1965) 47-57, doi:10.1016/0020-7225(65)90019-4.

[57] H.R. von Gaertner, Die kristallstrukturen von loparit und pyrochlor, zentralblatt fuer mineralogie, geologie und palaeontologie, Abt. A (Teil 1) 61 (1930) 1-30 COD ID 1011128.

[58] S.R. Bishop, D. Marrocchelli, C. Chatzichristodoulou, N.H. Perry, M.B. Mogensen, H.L. Tuller, E.D. Wachsman, Chemical Expansion, Implications for electrochemical energy storage and conversion devices, Annu. Rev. Mater. Res. 44 (2014) 205-239, doi:10.1146/annurev-matsci-070813-113329.

[59] S.G. Viladkar, U. Bismayer, P. Zietlow, Metamict U-rich pyrochlore of newania carbonatite, Udaipur, Rajasthan, J. Geol. Soc. India 89 (2017) 133-138, doi:10.1007/s12594-017-0576-0.

[60] M.T. Vandenborre, E. Husson, J.P. Chatry, D. Michel, Rare-earth titanates and stannates of pyrochlore structure; vibrational spectra and force fields, J. Raman Spectrosc. 14 (1983) 63-71, doi:10.1002/jrs.1250140202.

[61] D.J. Arenas, L.V. Gasparov, Wei Qiu, J.C. Nino, C.H. Patterson, D.B. Tanner, Raman study of phonon modes in bismuth pyrochlores, Phys. Rev. B 82 (2010) 214302 , doi:10.1103/PhysRevB.82.214302.

[62] B.P. Mandal, P.S.R. Krishna, A.K. Tyagi, Order-disorder transition in the $\mathrm{Nd}_{2-\mathrm{y}} \mathrm{Y}_{\mathrm{y}} \mathrm{Zr}_{2} \mathrm{O}_{7}$ system: probed by X-ray diffraction and Raman spectroscopy, J. Solid State Chem 183 (2010) 41-45, doi:10.1016/j.jssc.2009.10.010.

[63] M. Gaft, R. Reisfeld, G. Panczer, Modern Luminescence Spectroscopy of Minerals and Materials, 2nd ed., Springer, Switzerland, 2015.

[64] T. Beirau, A. Shelyug, A. Navrotsky, H. Pöllmann, E.K.H. Salje, Avalanches during recrystallization in radiation-damaged pyrochlore and allanite: statistical similarity to phase transitions in functional materials, Appl. Phys. Lett. 115 (2019) 231904, doi:10.1063/1.5133439.

[65] C.E. Reissner, U. Bismayer, D. Kern, M. Reissner, S. Park, J. Zhang, R.C. Ewing, A. Shelyug, A. Navrotsky, C. Paulmann, R. Škoda, L.A. Groat, H. Pöllmann, T. Beirau, Mechanical and structural properties of radiation-damaged allanite-(Ce) and the effects of thermal annealing, Phys. Chem. Miner. 46 (2019) 921-933, doi:10.1007/s00269-019-01051-z.

[66] T. Beirau, W.D. Nix, R.C. Ewing, G.A. Schneider, L.A. Groat, E. Bismayer, Mechanical properties of natural radiation-damaged titanite and temperature-induced structural reorganization: a nanoindentation and Raman spectroscopic study, Am. Miner. 101 (2016) 399-406, doi:10.2138/am-2016-5433.

[67] E.K.H. Salje, D.J. Safarik, R.D. Taylor, M.P. Pasternak, K.A. Modic, L.A. Groat, J.C. Lashley, Determination of Iron Sites and the Amount of Amorphization In Radiation-Damaged Titanite (CaSiTiO5), 23 (2011) 105402, 10.1088/0953$8984 / 23 / 10 / 105402$

[68] E.J. Weber, R.C. Ewing, Plutonium immobilization and radiation effects, Science 289 (2000) 2051-2052, doi:10.1126/science.289.5487.2051. 